\title{
Soluble Interleukin-1 Receptor Type I Measurement
}

National Cancer Institute

\section{Source}

National Cancer Institute. Soluble Interleukin-1 Receptor Type I Measurement. NCI

Thesaurus. Code C117836.

The determination of the amount of soluble interleukin-1 receptor type I present in a sample. 